ISSN 1810-3030 (Print) 2408-8684 (Online)

\title{
Non-destructive maturity index of “Amritsagor” banana using RGB and HSV values
}

\author{
F. A. Toma ${ }^{1}$, R. Ahmmed ${ }^{2}$, M. F. Hasan ${ }^{3}$, M. R. Haque ${ }^{4}$, M. B. Monju ${ }^{5}$ and M. S. H. Surovi ${ }^{6}$ \\ ${ }^{1}$ Department of Food Technology and Engineering, Patuakhali Science and Technology University, Dumki, Patuakhali, \\ Bangladesh \\ ${ }^{2}$ Department of Food Engineering, Dhaka University of Engineering and Technology, Gazipur-1707, Bangladesh \\ ${ }^{3}$ Department of Horticulture, Patuakhali Science and Technology University, Dumki, Patuakhali, Bangladesh \\ ${ }^{4}$ Department of Biochemistry and Food Analysis, Patuakhali Science and Technology University, Dumki, Patuakhali, Bangladesh \\ ${ }^{5}$ Department of Food Technology and Rural Industries, Bangladesh Agricultural University, Mymensingh-2202, Bangladesh \\ ${ }^{6}$ Department of Farm Power and Machinery, Bangladesh Agricultural University, Mymensingh-2202, Bangladesh
}

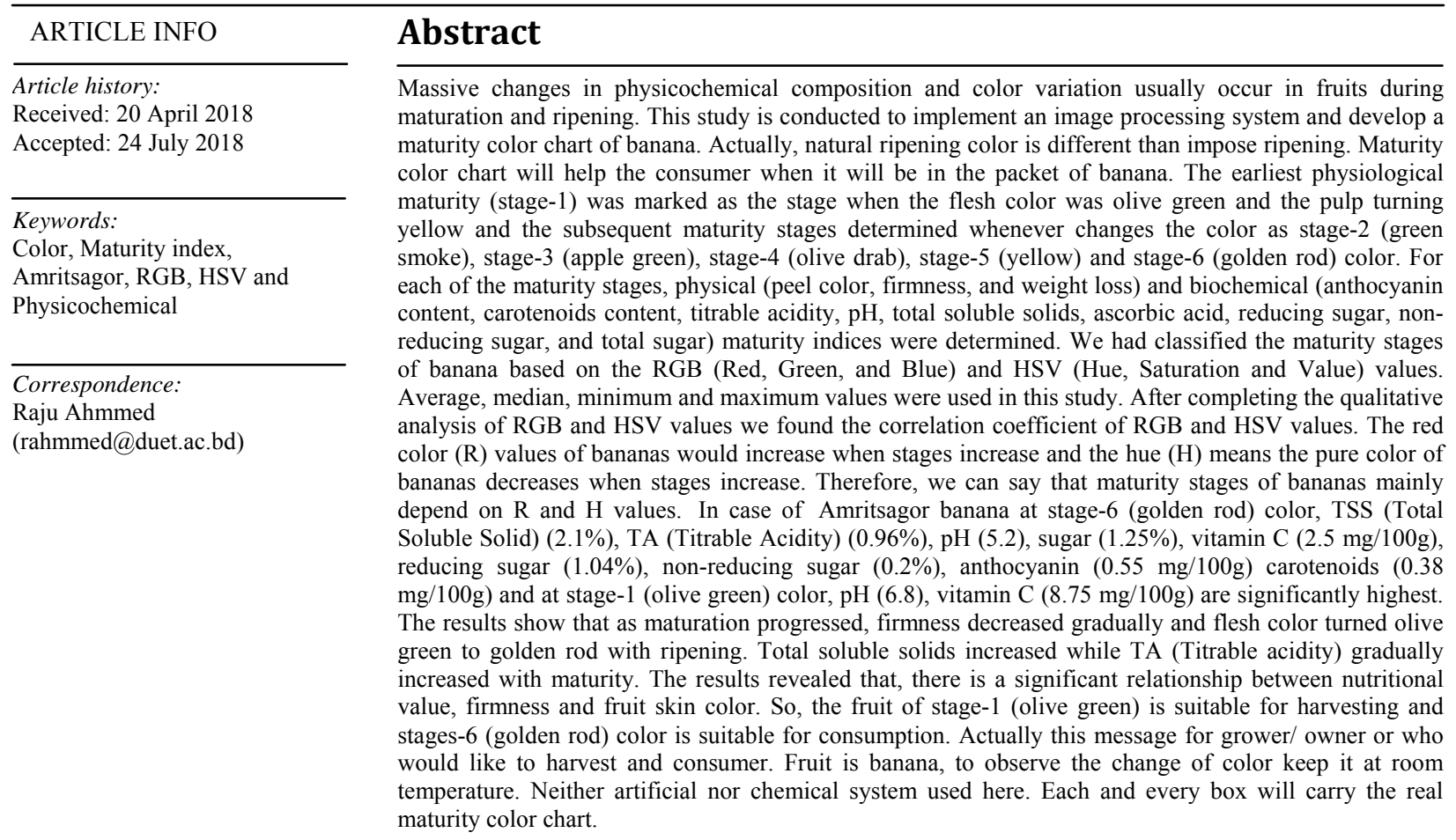

\section{Introduction}

Bananas are the fifth most important agriculture commodity in world trade after cereals, sugar, coffee and cocoa (Dadzie and Orchard 1997). The fruit is variable in size, color and firmness, but is usually elongated and curved, with soft flesh rich in starch covered with a rind which may be green, yellow, red, purple, or brown when ripe. Almost all modern edible parthenocarpic (seedless) bananas come from two wild species - Musa acuminata and Musa balbisiana. Amritsagor banana (Musa paradisiaca) usually harvested at the matured green stage and they remain firm and green without significant changes in peel color, texture or composition (Aguilera et al., 2003). Maturity stage at harvest of fresh banana fruit is an important factor that affects the fruit quality during marketing.
Bananas are extremely healthy and delicious. It contains several essential nutrients, and has benefits for digestion, heart health and weight loss. Banana is one of the high calories, tropical fruits. Hundred grams of fruit carry ninety calories (Ortiz et al., 1995). Besides, it contains good amount carbohydrates, proteins, phenols, $\beta$ carotene, minerals ( $\mathrm{Na}, \mathrm{K}, \mathrm{Ca}, \mathrm{Mg}, \mathrm{P}, \mathrm{Fe}, \mathrm{Zn}, \mathrm{B}, \mathrm{Cu}$, and $\mathrm{Mn}$ ), and vitamin C (Sunil pareek, 2016).

The changes occurred during ripening are in physical, mechanical and chemical properties of banana fruits. Skin color changes from green to yellow, firmness is decreased, fruit gets softened and starch is converted into sugar. Commercial standard color charts are available for (Musa sp var 'Robusta') varieties of banana, in which 6 stages of peel color were reproduced and translated to a numerical scale where Stage- $1=$ all 
green, Stage- $2=$ green with trace of yellow, Stage-3 = more green than yellow, Stage- $4=$ more yellow than green, Stage- $5=$ yellow with trace of green, and Stage- 6 $=$ full yellow. According to color chart, in terms of peel color slight difference occurs among the advanced stages of maturity i.e. stage 5 and 6 as compared to initial stages. Knowing the physical and mechanical properties of banana fruit and changes in these parameters during different ripening stages is the most important attributes to design handling, sorting, peeling, processing and packaging system. The ability to identify maturity of fresh banana fruit will be a great support for farmers to optimize harvesting phase which helps to avoid harvesting either under-matured or over-matured banana (Surya and Kumar 2015). Some common physicochemical parameters used for this purpose are anthocyanine, firmness, acidity, total soluble solids and total sugar, reducing sugar and non-reducing sugar. Quantitative determination of chemical constituents is destructive and entails the use of chemicals and instruments which are relatively expensive. Since the ripening banana fruit changes color from green to yellow, orange or red, non-destructive methods based on photometry may be applied to quantitatively determine the degree of fruit ripeness. The surface color of a fruit is a major visual parameter that has been used traditionally to determine its ripeness. Maturity stages as well as degree of maturation of fresh bananas color may calculate using surface color of banana. The objectives of this study are:-

i. to evaluate the physical quality in relation to external color;

ii. to observe the chemical characteristics at different color stages of the Amritsagor banana fruits.

\section{Materials and Methods}

\section{Sample collection}

A total of 70 healthy bananas with uniform size shape and color were selected from tree of Amrita sagor banana plant belonging to the BADC (Bangladesh Agricultural Development Corporation) farm at Lakutia in Barisal. Fruits were carried out to the Postharvest laboratory, Department of Horticulture, Patuakhali Science and Technology University (PSTU). After harvesting, immediately we started our job. The bananas were harvested at stage- 1 and then the changes in the bananas stages were observed and monitored carefully once a day. At each maturity stage of these bananas, the sample images were captured and determined physical and chemical characteristics.

Determination of color: At first a total of 70 green bananas images were acquired with a resolution of 13 mega pixels using camera of ASUS_X008. To measure color of stages, 3 replications were used for each stage. Each replication containing 4 fruits total 12 fruits. Sixty fruits were used for Stage $2-6(5 \times 12=60)$. For initial data and other uses 10 fruits were used. The images were captured between 9AM to 2PM whenever changed the color of fruits using natural light under ambient temperature. A white background was used so that segmentation can be done easily. The color of bananas peels was determined using an Android Application Software namely "On Color Measure" (developed by potato tree Soft, Version 3.0) equipped with an aim pointer. A white background was used so that segmentation can be done easily. Images could be captured at $9 \mathrm{~cm}$ distances. It provides the easiest way to store the information of each color detection. Color measurements were done at each face of banana and a mean value was obtained. The bananas color determination were expressed in chromaticity values of Red $\left(\mathrm{R}^{*}\right)$, Green $\left(\mathrm{G}^{*}\right)$ and Blue $\left(\mathrm{B}^{*}\right)$. For measuring the color the camera was aimed at the target color point and clicked on crosshair pointer and moved it to any place on the screen. The dashboard displays the information of the color detected. Grab button was clicked to capture the screen image and saved all the detailed color information RGB, color names and screen images.

Weight loss: The weight loss was determined with an electronic balance (Model-668ALED, RFL). Seven bananas per treatment represented seven replications were marked for this purpose and the same banana was used until the end of the experimental period. The percentage of weight loss was calculated using the following formula:

Weight Loss $(\%)=\frac{\mathrm{w}_{1}-\mathrm{w}_{2}}{\mathrm{w}_{1}} \times 100$

Where, $\mathrm{W}_{1}=$ Initial weight of the fruit; $\mathrm{W}_{2}=$ Weight of fruits at various storage periods.

Determination of firmness (N): Firmness of banana was measured using the digital fruit firmness testing machine (Model GY-802). The instrument was equipped with a $4 \mathrm{~mm}$ diameter cylindrical probe that was penetrated in the normal direction. The reading was taken for each fruit at collar, middle and end points according to Hassan (2006).

Determination of titrable acidity (\% Citric Acid): The titrable acidity was estimated through the chemical analysis using banana pulp. The titrable acidity of banana was determined according to Ranganna (1979).

Determination of total soluble solid (TSS) concentration: The total solids concentration of banana pulp was determined using a refractometer (Model N-1, BOECO Germany). The remaining of the filtrated juice from TA determination was used to measure the soluble solid content (SSC) of the pulp. Before measurement, the refractometer was calibrated with distilled water to give a $0 \%$ reading. About $1-2$ drops of the filtrate was placed on the prism glass of the refractometer to obtain the percentage of soluble solid content (SSC) reading. The readings were multiplied by the by dilution factor to obtain the original percentage of the pulp tissues. Since differences in sample temperature could affect the measurement of soluble solid content (SSC). 
Determination of $\mathbf{p H}$ : The remaining of the filtrated juice from titrable acidity (TA) determination was used to measure the $\mathrm{pH}$ of the banana pulp. The $\mathrm{pH}$ was determined using a glass electrode $\mathrm{pH}$ meter (GPL 21, Crison, Bercelona, EEC). Before being used, the $\mathrm{pH}$ meter was calibrated with buffers at $\mathrm{pH} 4.0$ followed by $\mathrm{pH}$ 7.0. After that, the glass electrode was placed into the filtrate to measure the $\mathrm{pH}$ and stabilized reading was recorded. For accuracy of the reading, the glass electrode was washed after each reading with distilled water and wiped to dry with soft tissue paper.

Determination of the ascorbic acid (Vitamin C): The ascorbic acid content was determined according to Ranganna (1979). The following equation was used for the estimation of ascorbic acid content-

Ascorbic acid $\left(\mathrm{mg} 100 \mathrm{~g}^{-1}\right)=$

Titre $(\mathrm{ml}) \times$ dye factor $(0.125) \times$ volume made up $(50 \mathrm{ml}) \times 100$

Aliquorusad for estamitation $(5 \mathrm{ml}) \times$ sample weight $(10 \mathrm{~g})$

Sugar Content: The sugar content of the banana pulp was determined according to the method of Ranganna (1986).

Reducing sugar content: Percentage of the reducing sugar was calculated according to the following formula-

Reducing sugar content $(\%)=\frac{\mathrm{F} \times \mathrm{D} \times 100}{\mathrm{~T} \times \mathrm{W} \times 1000}$

Where,

$\mathrm{F}=$ Fehling's factor

$\mathrm{D}=$ Dilution

$\mathrm{T}=$ Titre and

$\mathrm{W}=$ Weight or volume of the sample

- Titration of the total invert sugar: Fifty milliliters purified solution was taken in a $250 \mathrm{ml}$ conical flask. Five grams of citric acid and $50 \mathrm{ml}$ distilled water was added to it. The conical flask containing sugar solution was boiled for inversion of sucrose and finally cooled. Then the solution was transferred to a $250 \mathrm{ml}$ volumetric flask and neutralized by $1 \mathrm{~N}$ $\mathrm{NaOH}$ using the phenolphthalein indicator. The volume was made up to the mark with distilled water. Then the mixed Fehling's solution was titrated using similar procedure followed as in the case of invert sugar (reducing sugar) mentioned earlier. The percentage of the total invert sugar was calculated using the formula used in case of reducing sugar.

\section{- Non- reducing sugar:}

The percentage of non-reducing sugar $=$ Percentage of total sugar - Percentage of reducing sugar.

- Estimation of total sugar: The total sugar was calculated as follows:

Percentage total sugar $=$ Percentage of reducing sugar

+ Percentage of non-reducing sugar.

Determination total anthocyanine: Total anthocyanine content of banana peel and the carotinoid content of pulp were determined as per Sims and Gamon (2002). For anthocyanine and carotenoid measurement, $5 \mathrm{mg}$ tissue samples were properly homogenized with $10 \mathrm{ml}$ in $80 \%$ cold acetone and centrifuged for $4 \mathrm{~min}$ at $800 \mathrm{rpm}$ at $4^{\circ} \mathrm{C}$. The clear supernatant diluted to a final volume of 5 $\mathrm{ml}$ with additional acetone and was used for the estimation of total anthocyanin content, carotenoid content and evaluated for antioxidant activity. The absorbance of the extract solutions was measured at 665 $\mathrm{nm}, 649 \mathrm{~nm}, 646 \mathrm{~nm}, 663 \mathrm{~nm}, 470 \mathrm{~nm}, 529 \mathrm{~nm}$ and 650 $\mathrm{nm}$ wavelengths with a double beam spectrophotometer (Dynamica HALO-DB-20S UV-VIS Double Beam Spectrophotometer). Content of anthocyanine content was calculated by using the following formula:

Anthocyanine $(\mu \mathrm{mol} / \mathrm{ml})=\mathrm{A}_{529}-0.288 \mathrm{~A}_{650}$

Anthocyanine $(\mu \mathrm{mol} / \mathrm{g} \times 207.247=\mu \mathrm{g} / \mathrm{g})=\mathrm{A}_{529}-0.288 \mathrm{~A}_{650}$

Where Ax is the absorbance of the extract solution in a $1-\mathrm{cm}$ path length cuvette at wavelength $\mathrm{x}$.

Image analysis: The images of bananas were analyzed by an Android Application Software namely "On Color Measure" (developed by potatotree Soft, Version 3.0). We have implemented a rule of based method to classify bananas according to their maturity stages based on the RGB and HSV values. Average, median, min and max values are used in this study. After the qualitative analysis of RGB and HSV values we found the correlation coefficient of RGB and HSV values.

Statistical analysis: The recorded data on different parameters of the experiment were tabulated and analyzed with appropriate design of experiment (Gomez and Gomez, 1984) adopting a statistical programme MSTAT-C. All the treatment means were calculated and the analysis of variances (ANOVA) of different characters considered was done by the help of Duncan's Multiple Range Test (DMRT). The means were separated by Least Significant Difference (LSD) test at $1 \%$ and $5 \%$ levels of significance.

\section{Results and Discussion}

The results of the analysis of variance in respect of all parameters studied in the present investigation have been presented and discussed below:

\section{Studies on the physical characteristics at different stages of the fruits}

Peel color: Color change is the result of pigments, which were always present in the fruit, becoming visible when chlorophyll is degraded. However, additional pigments are also produced by the fruit as it ripens. In fruit, the cell walls are mainly composed of polysaccharides including pectin. During ripening, a lot of the pectin is converted from a water-insoluble form to a soluble one by certain degrading enzymes.

Change of peel color during ripening and senescence of fruits involves chlorophyll degradation or qualitative and quantitative alternation of the green pigment into other pigments. During color change the pulp becomes softer and sweeter as the ratio of the sugar to starch increased. 


\section{Classification result using RGB and HSV values}

We have implemented a rule based method to classify bananas according to their maturity stages based on the RGB and HSV values. Average, median, min and max values are used in this case. After the qualitative analysis of RGB and HSV values we found the correlation coefficient of RGB and HSV values. The value of the correlation coefficient for $\mathrm{R}$ values and the stage numbers is 0.408587 which means $\mathrm{R}$ has positive moderate linear correlation with the stage number. $G=$ 0.22843 that means $G$ has negative weak linear correlation and $\mathrm{B}=-0.23761$ indicating that $\mathrm{B}$ has also negatively weak linear relationship. To improve the classification accuracy, the RGB values have been converted into HSV values as it resembles the color sensing properties of human vision. Here the value of the correlation coefficient for $\mathrm{H}$ values and the stage numbers is -0.88926 which means $\mathrm{H}$ has negative strong linear relationship. On the other hand $S=-0.284792$ which shows positive weak relationship and $\mathrm{V}=$ 0.070647 indicating no linear relationship with the stage number. Therefore, we can say that maturity stages of bananas mainly depend on $\mathrm{R}$ and $\mathrm{H}$ values. Here red color values of bananas would increase when stages increase and hue means pure color of bananas decreases when stages increase.

This correlation is also similar to our manual observation as bananas become more yellowish with the advancement of the stages. The yellow color is a combination of green and red. Therefore, increase of red color values with the stage numbers is reasonable. Also, in the higher stages, especially in stage 6 , the number of color pigments reduces and thus the hue values (pure color measures) decrease with the increase of stages. Hence, this strong negative correlation between the hue values and the stage numbers is also reasonable.

Weight loss: The changes in weight of banana are shown in Fig. 3.

Significant variation was observed in respect of total weight loss at different maturity stages of the fruits. The highest weight loss was $1.190 \%$ at the stage- 6 and lowest weight loss was $1.120 \%$ at the stage- 1 (Table 2). The weight loss of the fruits was occurred due to the loss of water from the fruits, microbial decay and storage environment like temperature and humidity and respiration. Decreases the weight of banana at high temperature during ripening and storage. The percent of the weight loss was increased continuously during ripening due to a high storage temperature. Since high energy is required to run the process, starch is converted to sugar and used as energy. The excess energy produced from the respiration process is released from the tissue by the vaporization of water, which will subsequently be transpired from the fruit, causing a weight loss.

\section{Firmness}

Firmness is important criteria of fruits quality. The firmness of banana pulp from stage- 1 to stage- 6 is an obvious change during storage. During firmness change the pulp become softer and sweeter as the ratio of the sugar to starch increases. The change of the firmness of banana at different maturity stage is shown in (Fig. 4).

During matured stage i.e. when banana was green the firmness was high. Firmness decreases as ripening continued. The maximum firmness was $31.50 \mathrm{~N}$ at stage-1 and lowest value $10.02 \mathrm{~N}$ at stage 2 (Table 2). Significant difference was observed among stage-1 to stage- 6 . Softening of fruits is related to a change in cell wall component and starch degradation (Seymour, 1993). The starch granules, packed in the tissue of banana flesh give rise to the toughness of the unripe fruit, and are hydrolyzed to sugar while an increase of the cell wall solubility allows water and nutrients to pass in and out of the cells. Fruit firmness decreased steadily during the six-day storage. It was expected that during those periods all starch would be completely converted to sugar.

\section{Bio-chemical characteristics at different stages of the fruits}

Titrable acidity: The titrable acidity content of fruits varied significantly (Table 2) at different stages during storage. In banana flesh, the total amount of acid increases during ripening; the main acids being: malic, citric and oxalic acid. While the first two acids are responsible for tartness in the unripe banana, oxalic acid is contributed to astringent taste of the fruit (Seymour, 1993). As the fruit ripened, these acids were reduced and, the taste changed to a sweet taste, mainly from the hydrolyzed sugar from the starch degradation. The titrable acidity is increased from 0.51 to a peak of 0.96 up to sixth day (Fig. 5 and Table 2).

pH: The $\mathrm{pH}$ of the fruit pulp at different stages of maturity varied significantly (Fig. 5) at different stages during storage. The $\mathrm{pH}$ of the fruit pulp at different stages under the study varied from 5.2-6.8 depending on varieties and maturity stages (Table 2). The $\mathrm{pH}$ of banana was gradually decreased from stage- 1 to stages6 . The highest $\mathrm{pH}$ was recorded at the stage-1 (6.8), and the lowest $\mathrm{pH}$ (5) was recorded at stage-6. The reduction of $\mathrm{pH}$ may be due to continuous increases of acidity during ripening. Significant difference of $\mathrm{pH}$ was observed among stage- 1 to stage- 6 . $\mathrm{pH}$ influences the catalytic activity of cell wall enzymes and can have a profound effect on anthocyanin stability and color expression. The reduction of $\mathrm{pH}$ may be due to continuous increases of acidity during ripening. The highest $\mathrm{pH}$ content in Amrapali is recorded (4.54) while Mallika contain (4.09) when ripening and the lowest $\mathrm{pH}$ content in Mallika is recorded (2.79) while Amrapali (3.96) in unripen condition. Statistically highly significant variation of pulp $\mathrm{pH}$ was observed at different stages due to conversion of pectin into sugars. (Asutosh et al., 2016). 
Table 1. Pearson's correlation coefficient between the stage numbers and the color values

\begin{tabular}{cc}
\hline Color & Stages \\
\hline R & 0.408587 \\
G & -0.22843 \\
B & -0.23761 \\
H & -0.88926 \\
S & 0.284792 \\
V & 0.070647 \\
\hline
\end{tabular}

Table 2. Duncan's multiple range test (DMRT) value for weight loss, firmness, titrable acidity (TA), pH, total soluble solid (TSS) and vitamin $C$ content at different maturity stages of Amrit sagor banana

\begin{tabular}{ccccccc}
\hline Stages & $\begin{array}{c}\text { Weight } \\
\text { Loss (\%) }\end{array}$ & $\begin{array}{c}\text { Firmness } \\
(\mathrm{N})\end{array}$ & $\begin{array}{c}\text { TA } \\
(\%)\end{array}$ & pH & $\begin{array}{c}\text { TSS } \\
(\%)\end{array}$ & $\begin{array}{c}\text { Vit C } \\
(\mathrm{mg} / 100 \mathrm{~g})\end{array}$ \\
\hline Stage 1 & $1.120^{\mathrm{f}}$ & $31.50^{\mathrm{a}}$ & $0.510^{\mathrm{f}}$ & $6.80^{\mathrm{a}}$ & $0.01^{\mathrm{f}}$ & $8.75^{\mathrm{a}}$ \\
Stage 2 & $1.130^{\mathrm{e}}$ & $28.45^{\mathrm{b}}$ & $0.570^{\mathrm{e}}$ & $5.97^{\mathrm{b}}$ & $0.6^{\mathrm{e}}$ & $7.50^{\mathrm{b}}$ \\
Stage 3 & $1.140^{\mathrm{d}}$ & $24.58^{\mathrm{c}}$ & $0.640^{\mathrm{d}}$ & $5.86^{\mathrm{c}}$ & $0.87^{\mathrm{d}}$ & $6.25^{\mathrm{c}}$ \\
Stage 4 & $1.160^{\mathrm{c}}$ & $20.30^{\mathrm{d}}$ & $0.762^{\mathrm{c}}$ & $5.72^{\mathrm{d}}$ & $1.5^{\mathrm{c}}$ & $5.72^{\mathrm{d}}$ \\
Stage 5 & $1.170^{\mathrm{b}}$ & $15.05^{\mathrm{e}}$ & $0.830^{\mathrm{b}}$ & $5.62^{\mathrm{e}}$ & $1.8^{\mathrm{b}}$ & $3.75^{\mathrm{e}}$ \\
Stage 6 & $1.190^{\mathrm{a}}$ & $10.02^{\mathrm{f}}$ & $0.960^{\mathrm{a}}$ & $5.20^{\mathrm{f}}$ & $2.1^{\mathrm{a}}$ & $2.50^{\mathrm{f}}$ \\
LSD & 0.1486 & 0.7676 & 0.046 & 0.093 & 0.105 & 0.066 \\
CV (\%) & 0.29 & 2.39 & 0.72 & 1.07 & 6.08 & 0.83 \\
\hline
\end{tabular}

Significant at $1 \%$ level of probability

\section{Total soluble solid (TSS)}

The TSS content of fruits varied significantly at different stages during storage. The TSS content of fruit at different stages under the study was increased depending on maturity stages (Fig. 7).

The highest sugar content was recorded $2.1 \%$ at stage- 6 and the lowest sugar content was recorded $0.01 \%$ at stage-1 (Table 2). In most ripen fruits including banana, incidence of post-harvest causes sugar formation as a result of starch hydrolysis. During the development of the flesh of a fruit, in many species, nutrients are deposited as starch, which during the ripening process is transformed into sugars. The progression of the ripening process leads to increasing sugar levels. In the flesh more movement of water and the degradation of starch to soluble sugar within the cell contributed to the increase of TSS. (Salvador et al., 2007).

\section{Vitamin C}

The ascorbic acid (vitamin C) content of fruits varied significantly at different stages during storage. The vitamin $\mathrm{C}$ content of fruit at different stages under the study varied from $2.5-8.75 \mathrm{mg} / 100 \mathrm{~g}$ depending on the maturity stages (Fig. 8).

The highest vitamin $\mathrm{C}$ content was $8.75 \mathrm{mg} / 100 \mathrm{~g}$ at stage- 1 and the lowest vitamin $\mathrm{C}$ content was recorded $2.5 \mathrm{mg} / 100 \mathrm{~g}$ at stage- 6 (Table 2). The vitamin C content of banana fruit is higher when it is slightly immature, and declines as the fruit hits peak ripeness. The value of vitamin $\mathrm{C}$ content significantly varies from different stage of ripening. In some fruits, the amount of vitamin $\mathrm{C}$ varies between different varieties of the same species (Romero and Rodriguez, 2012).

\section{Reducing sugar}

The reducing sugar content of fruit at different stages under the study varied significantly from $0.31-1.04 \%$ depending on maturity stages (Fig. 9). In case of Amritsagor banana, at stage-1, the lowest reducing sugar $(0.31 \%)$ was recorded followed by stage- $2(0.4 \%)$ and stage-3 $(0.5 \%)$. Then the reducing sugar was increased up to fully ripen and the highest reducing sugar $(1.04 \%)$ was recorded at stage- 6 and not greatly significant (Table 3). The increase in reducing sugar may be attributed to enzymatic conversion of starch to reducing sugar (Islam, 1998). Bhadra and Sen (1999) mentioned that the total sugar and reducing sugar contents increased with in the progress of the storage period.

\section{Non-reducing sugar}

The non-reducing sugar content of fruit at different stages under the study significantly varied from 0.08 $0.2 \%$ depending on maturity stages of banana (Figure 10). At stage-1, the lowest non reducing sugar $(0.08 \%)$ was recorded followed by stage- $2(0.09 \%)$ and stage- 3 $(0.1 \%)$. Then the non-reducing sugar was increased up to stage-6 significantly. The highest non reducing sugar $(0.2 \%)$ was recorded at stage-6. Rapidly increased nonreducing sugar was probably due to breakdown of starch into non-reducing sugar and then that non-reducing sugar was converted into reducing sugar resulting slowly increase in non-reducing sugar (Table 3). In mango, (Rangavalli et al., 1993) found a gradual increase in the non-reducing sugar content during its storage. Uddin et al., (2006) conducted an investigation on some biochemical characteristics of twenty two germplasm of mango. The non-reducing sugar content of the fruit pulp of mangoes varied from 2.34 to $5.95 \%$. A gradual increase in non-reducing sugar was observed with the advancement of maturity due to various enzymatic activities.

Table 3. Duncan's multiple range test (DMRT) value for reducing sugar, non-reducing sugar, total sugar, total anthocyanin and total carotenoids content at different maturity stages of Amrit sagor banana

\begin{tabular}{cccccc}
\hline Stages & $\begin{array}{c}\text { Reducing } \\
\text { Sugar } \\
(\%)\end{array}$ & $\begin{array}{c}\text { Non- } \\
\text { Reducing } \\
\text { Sugar }(\%)\end{array}$ & $\begin{array}{c}\text { Total } \\
\text { Sugar } \\
(\%)\end{array}$ & $\begin{array}{c}\text { Total } \\
\text { Anthocyanin } \\
(\mathrm{mg} / 100 \mathrm{~g})\end{array}$ & $\begin{array}{c}\text { Total } \\
\text { Carotenoids } \\
(\mathrm{mg} / 100 \mathrm{~g})\end{array}$ \\
\hline Stage 1 & $0.31^{\mathrm{e}}$ & $0.08^{\mathrm{c}}$ & $0.39^{\mathrm{e}}$ & $0.36^{\mathrm{d}}$ & $0.23^{\mathrm{d}}$ \\
Stage 2 & $0.32^{\mathrm{e}}$ & $0.08^{\mathrm{c}}$ & $0.41^{\mathrm{e}}$ & $0.37^{\mathrm{cd}}$ & $0.25^{\mathrm{cd}}$ \\
Stage 3 & $0.52^{\mathrm{d}}$ & $0.10^{\mathrm{c}}$ & $0.62^{\mathrm{d}}$ & $0.41^{\mathrm{c}}$ & $0.29^{\mathrm{bc}}$ \\
Stage 4 & $0.62^{\mathrm{c}}$ & $0.15^{\mathrm{b}}$ & $0.78^{\mathrm{c}}$ & $0.48^{\mathrm{b}}$ & $0.31^{\mathrm{b}}$ \\
Stage 5 & $0.69^{\mathrm{b}}$ & $0.19^{\mathrm{ab}}$ & $0.89^{\mathrm{b}}$ & $0.51^{\mathrm{ab}}$ & $0.36^{\mathrm{a}}$ \\
Stage 6 & $1.04^{\mathrm{a}}$ & $0.20^{\mathrm{a}}$ & $1.25^{\mathrm{a}}$ & $0.55^{\mathrm{a}}$ & $0.38^{\mathrm{a}}$ \\
LSD & 0.046 & 0.046 & 0.046 & 0.046 & 0.046 \\
CV (\%) & 0.40 & 0.00 & 0.46 & 0.99 & 1.69 \\
\hline
\end{tabular}

Significant at $1 \%$ level of probability 


\section{Total sugar}

The total sugar content of fruit at different stages under the study varied from $0.39-1.25 \%$ depending on maturity stages (Fig. 11). The lowest total sugar stage-1 (0.39\%) was recorded followed by stage- $2(0.41 \%)$ and stage-3 $(0.60 \%)$. Then the total sugar was increased up to fully ripen. The highest total sugar $(1.25 \%)$ was recorded at stage-6 (Table 3).

Zomo et al., (2014) observed that green bananas are almost all starch and have low sugar content and increased when ripening. As the bananas ripen, the starch content decreases, then sucrose appears. Next, fructose and glucose appear and increase. After about 6 days of ripening, sucrose begins to decline. The sugar content in overripe bananas can be dramatically higher than in bananas that are under ripe and optimally ripe. The results indicated that a progressive increase in total sugar content and decrease in starch content was observed during ripening. This could be due to the hydrolysis of starch into sugar during ripening. The most striking chemical changes occurred during the postharvest ripening of banana fruits were hydrolysis of starch and accumulation of sugars (Patil and Magar, 2006).

\section{Total anthocyanin content}

Anthocyanins have powerful antioxidant capability and are responsible for the color of banana. It was found that, the anthocyanin content was more in ripe banana peel and it was found highest at stage- $6(0.55 \mathrm{mg})$ and lowest in stage-1 $(0.36 \mathrm{mg})$ respectively (Fig. 12 and
Table 3). The anthocyanin content of fruits varied significantly at different stages during storage. In aqueous solution, anthocyanins undergo structural transformations that are $\mathrm{pH}-$ dependent. Anthocyanin below pH 2 exist primarily in the form of flavyllium cation. Processing and storage under low temperature can improve the stability of anthocyanins. When temperature is increased, anthocanins can be transformed into unstable formation of chalcone, and the chalcone is further degraded to brown products (Takeoka and Dao, 2002).

Total carotenoids content: Carotenoids, also called tetraterpenoids, are organic pigments. The carotenoids content of banana was increased at different stages during storage. The carotenoids content of fruit at different stages under the study varied from $0.23-0.38$ $\mathrm{mg} / 100 \mathrm{~g}$ depending on maturity stages of banana (Fig. 13). The lowest carotenoids at stage- $1(0.23 \mathrm{mg})$ and the highest carotenoids content $(0.38 \mathrm{mg})$ at stage- 6 (Table 2). The carotenoids content was increased very slowly up to fully ripen of fruits. As ripening proceeds, the green pigment of unripe banana is converted to carotenoids in ripe banana. It forms a non-enzymatic covalent bonding with chlorophyll thus its conversion to carotenoids. This explains why the levels of carotenoids increase with ripening. In carotenogenic fruits and fruit vegetables, ripening is usually accompanied by enhanced carotenogenesis as chlorophylls decompose and the chloroplasts are transformed into chromoplast (Gerard et al., 2009).

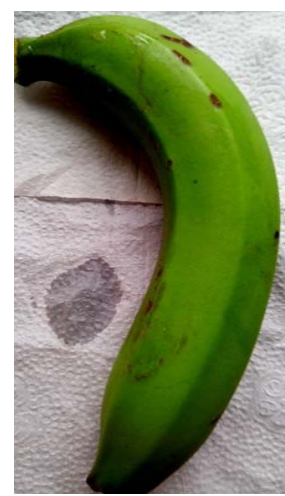

Stage-1

(Olive green)

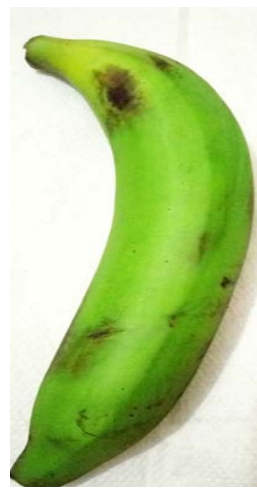

Stage-2 (Green smoke)

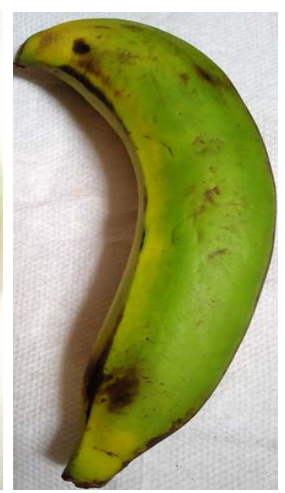

Stage-3 (Apple green)

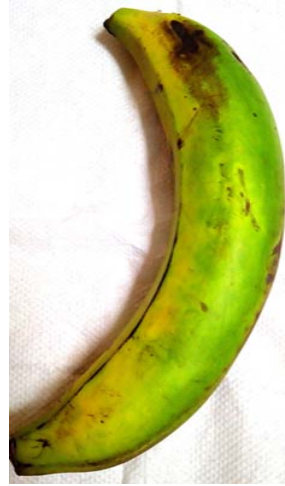

Stage-4
(Olive drab)
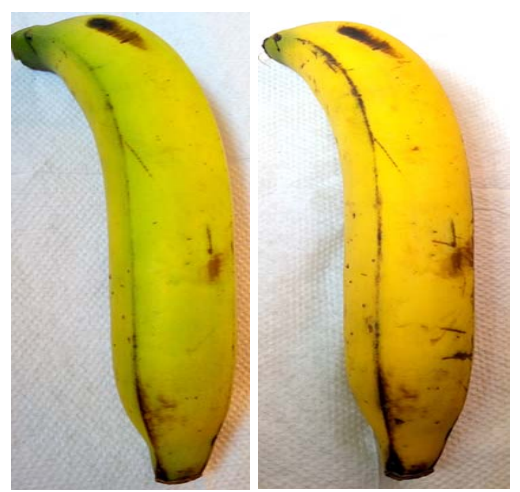

Stage-5 (Yellow)
Stage-6

(Golden rod)

Fig. 2. Different maturity stages of Amritsagor banana. 


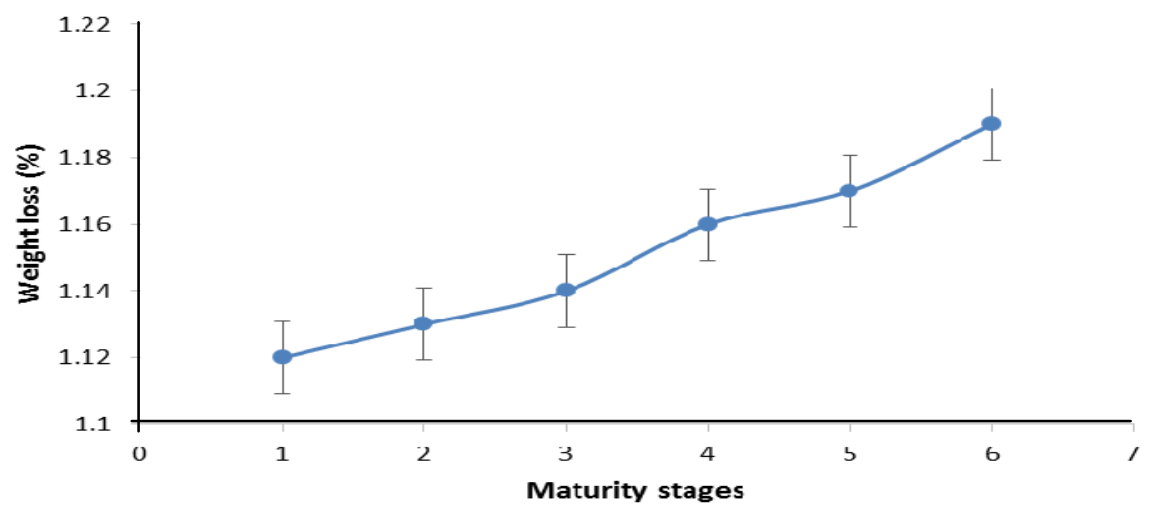

Fig. 3. Percent weight loss of Amritsagor banana at different maturity stages.

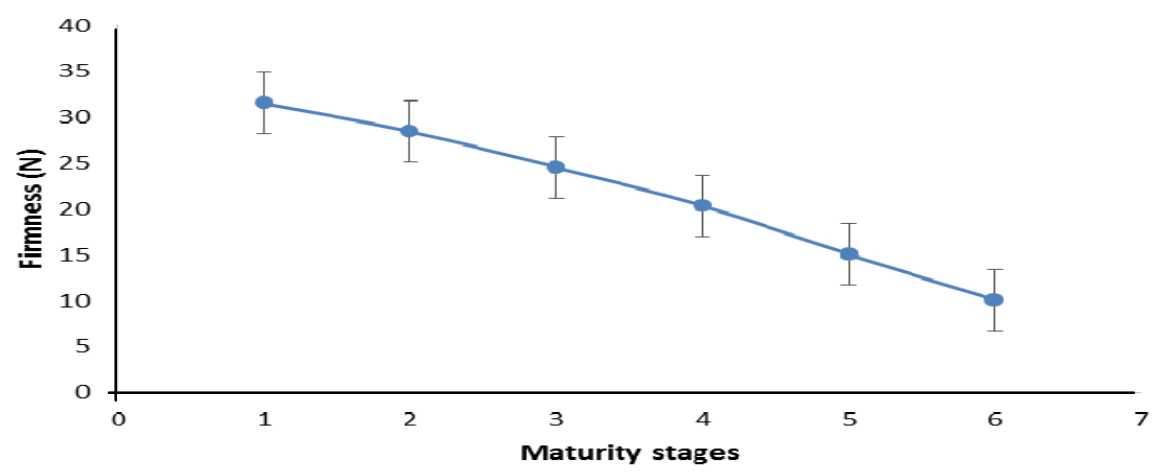

Fig. 4. Firmness of Amritsagor banana at different maturity stages.

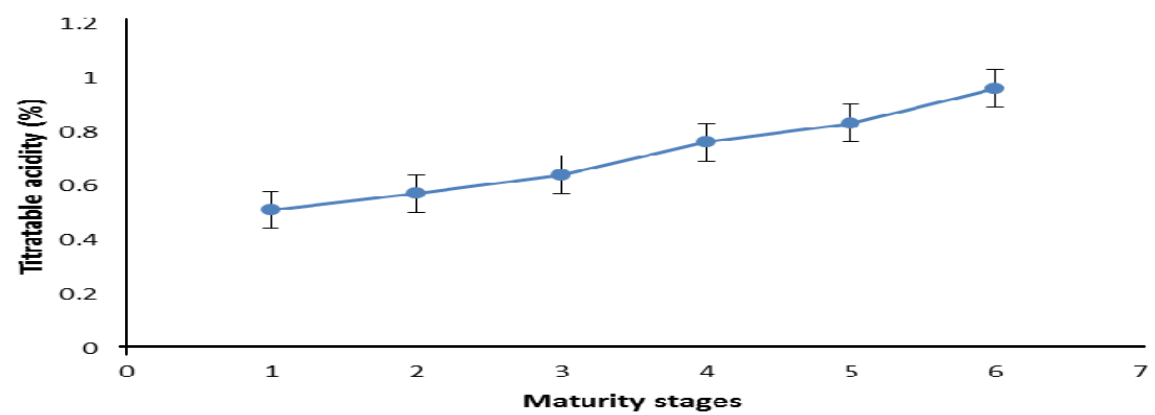

Fig. 5. Titrable acidity of Amritsagor banana pulp at different maturity stages.

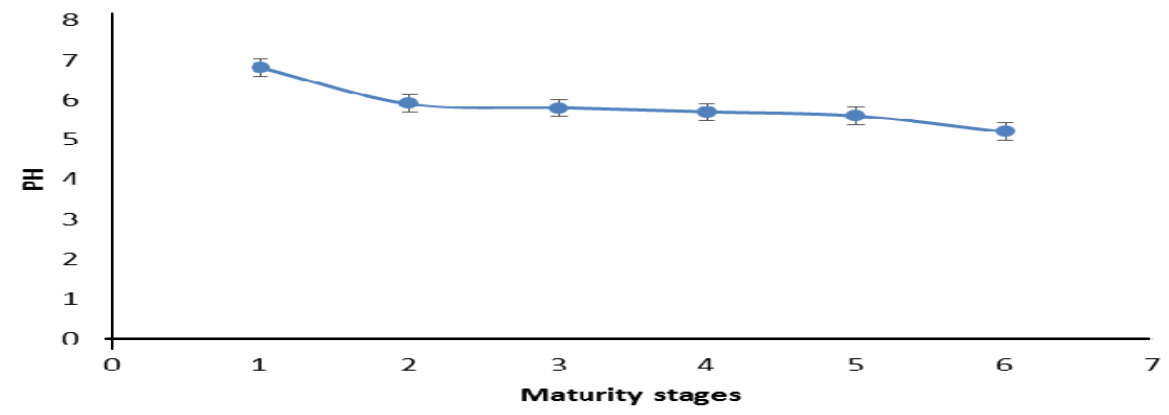

Fig. 6. pH of Amritsagor banana at different maturity stages. 


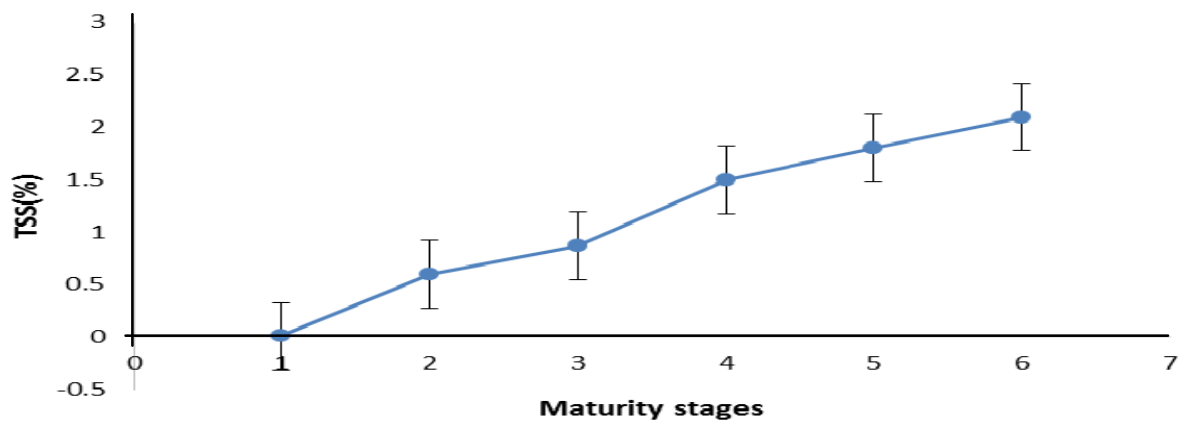

Fig. 7. TSS of Amritsagor banana pulp at different maturity stages.

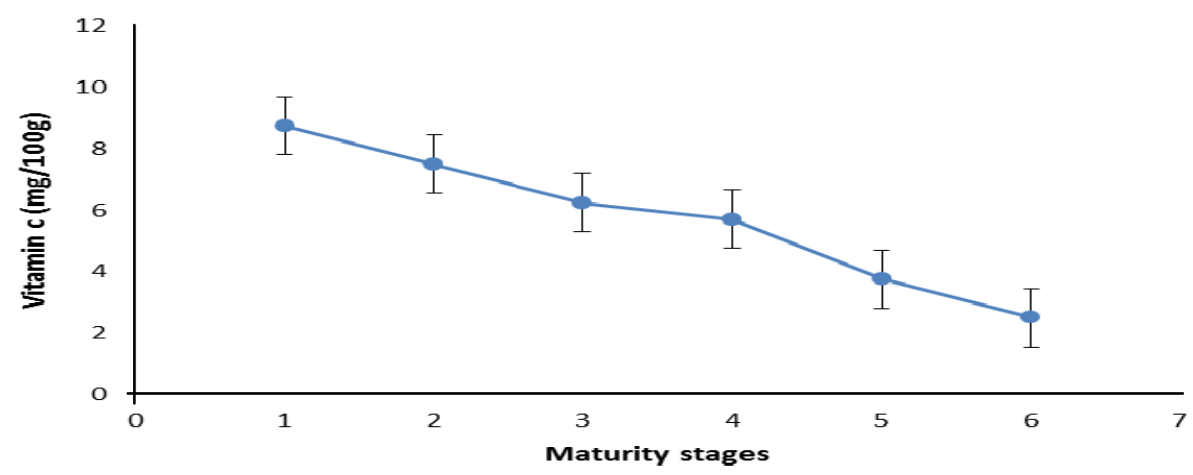

Fig. 8. Vitamin C content of Amritsagor banana pulp at different maturity stages.

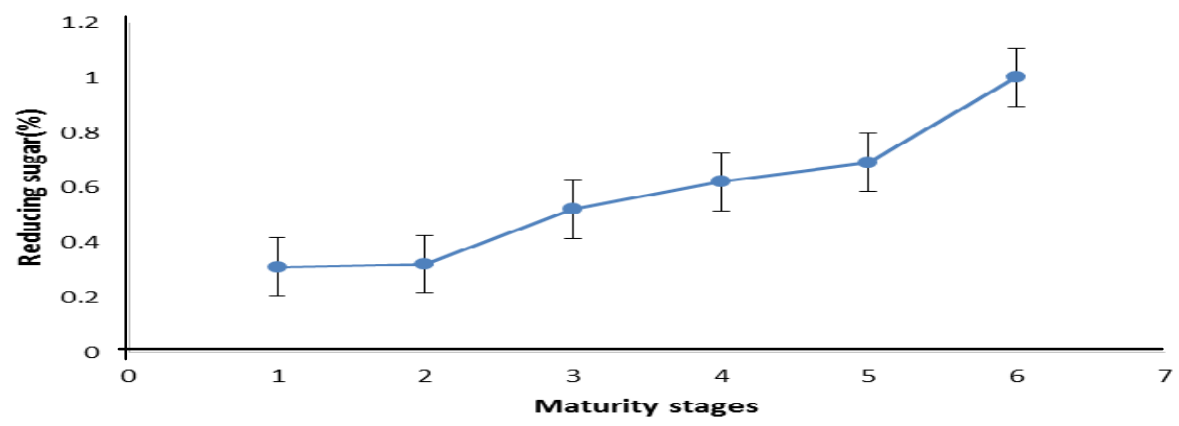

Fig. 9. Reducing sugar content of Amritsagor banana pulp at different maturity stages.

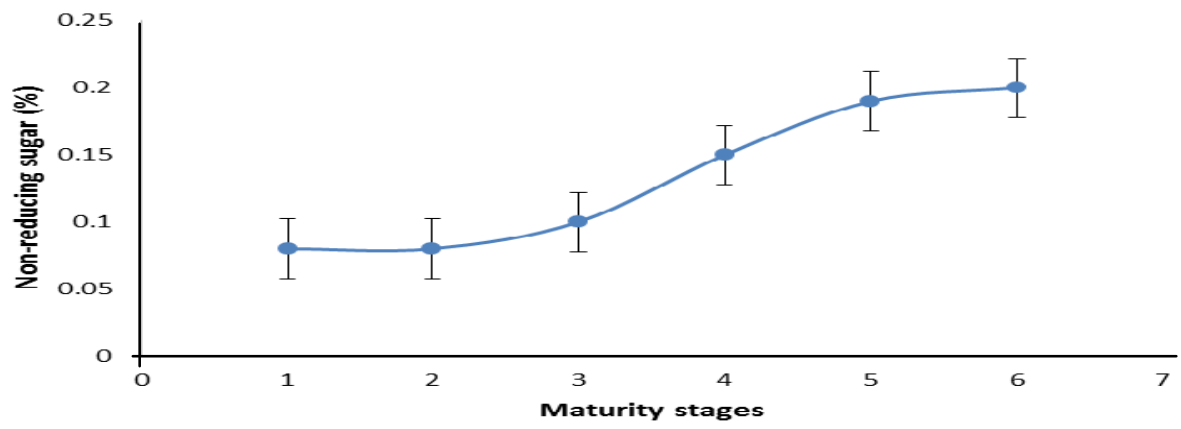

Fig. 10. Non-reducing sugar content of Amritsagor banana pulp at different maturity stages. 


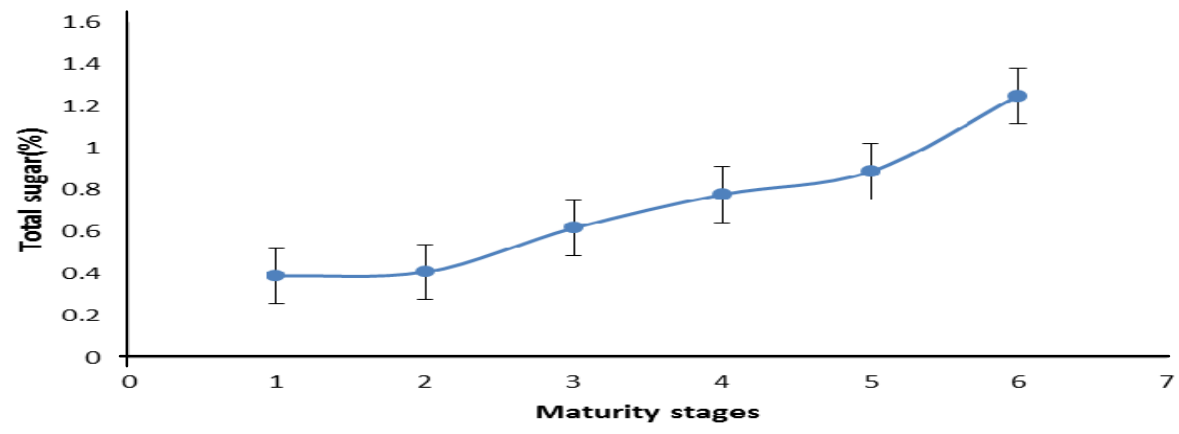

Fig. 11: Total sugar content of Amritsagor banana pulp at different maturity stages.

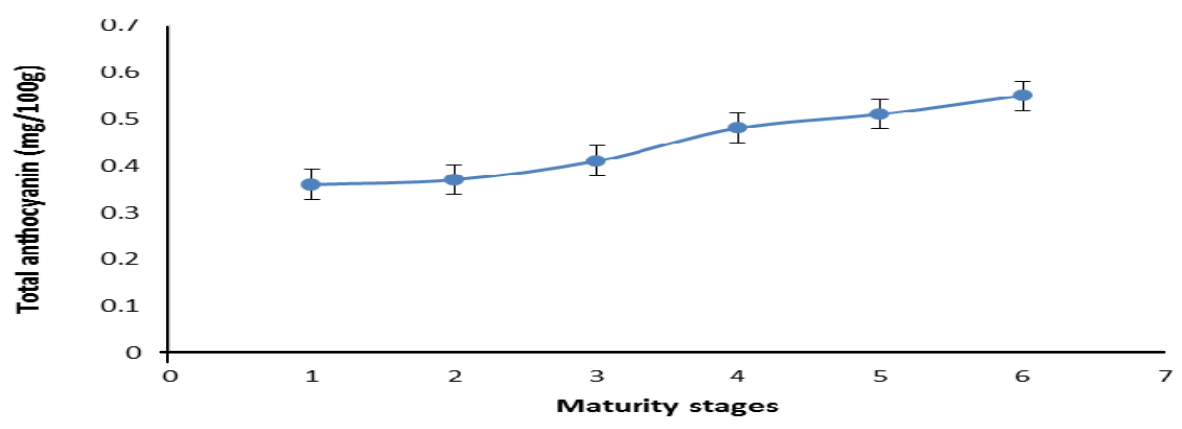

Fig. 12. Anthocyanin content of Amritsagor banana peel at different maturity stages.

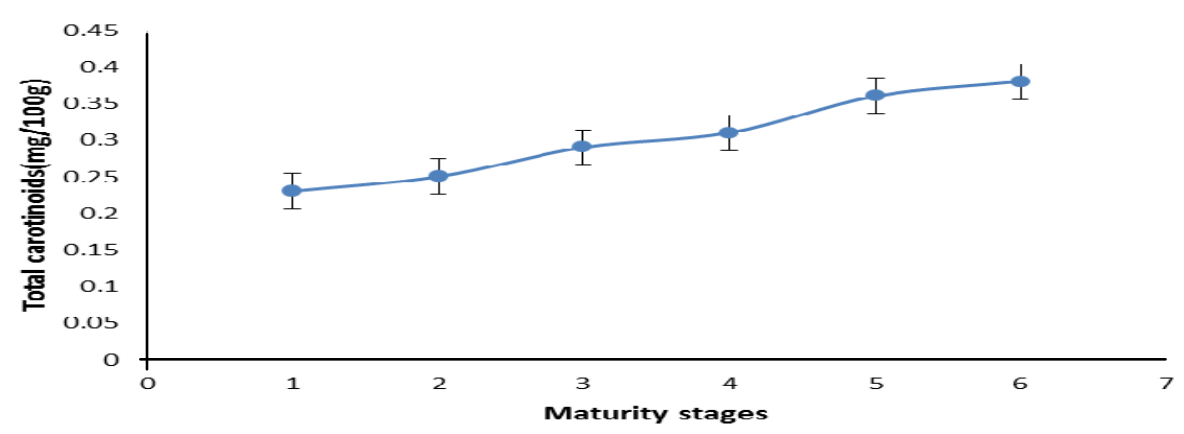

Fig. 13. Carotenoids content of Amritsagor banana peel at different maturity stages.

\section{Conclusion}

The present study was conducted to characterize the maturity stages and physicochemical properties of Amritsagor banana. Results showed the significant differences in color, firmness, $\mathrm{pH}$ and TSS subjected to the different stage of ripeness. However, it is important to select quality related attributes that best define the actual ripening stages to perform better classification in the production of banana. The producers, distributors and handlers, must be able to meet consumer demand with support from researchers, by developing advance post-harvest technologies that translate the related sensory attributes of specific physicochemical properties of the fruits. From the findings it could be concluded that the physical quality is highest at stage-1 (olive green). This stage is suitable for harvesting and transportation. The chemical composition is highest at stage-6 (golden rod) color and this stage is suitable for consumption.

\section{References}

Aguilera, Mendoza, F. and José, M. 2003. Classification of Bananas (Musa Cavendish) During Ripening by Computer Vision. Journal of Food Science, 45, pp.135-139.

Asutosh, Bhosale, Y.K. and Shanmugasundaram, S. 2016. Physicochemical changes during ripening of red banana. International Journal of Science, Environment and Technology. 5 (2), pp.1340-1348.

Bhadra, S. and Sen, S. K. 1999. Postharvest storage of custard apple (Annona squamosa L.) fruit var. Local Green under various chemical and wrapping treatments. 17(3), pp.710-713.

Dadzie, B.K. and Orchard, J.E. 1997. Routine Post-Harvest Screening of Banana/Plantain Hybrids: Criteria and Methods. INIBAP Technical Guidelines 2. International Plant Genetic Resources Institute, Rome, Italy 6, pp.5-30.

Gerard, Claudie, Juan and Kodjo, 2009. Carotenoid contents during ripening of banana hybrids and cultivars grown in Cameroon. 64 (4), pp.197-206. 
Gomez , K.A. and Gome, A.A. 1984. Statistical Procedures for Agric. Res. John Wiley and Sons, New York. pp. 680.

Hassan, M.K. 2006. Final Report: Postharvest loss Assessment: A Study to Formulate Policy for Postharvest Loss Reduction of fruits and Vegetables and Socio-Economic Uplift of the Stakeholders. pp. 188.

Islam, M.S. 1998. Storage life and quality of banana as affected by packaging and coating materials. M.S. thesis, Institute of Postgraduate Studies in Agriculture, Salna, Gazipur, Bangladesh.

Ortiz. R., Ferris, R.S.B. and Vuylsteke, D.R. 1995. Banana and Plantains (Ed. Gowen. S.). Chapman and Hall, London. pp.110-146.

Patil, D. L. and Magar, N. G. 2006. Physicochemical changes in banana fruit during ripening. Journal of Maharashtra Agricultural University, 1: pp.95-99.

Ranganna, 1979. Manual of Analysis of Fruit and vegeTable products. Tata Mc Graw Hill publishing company Ltd., New Delhi.

Ranganna, S. 1986. Handbook of Analysis and Quality Control for Fruit and VegeTable product, $2^{\text {nd }}$ Edn., Tata McGraw-Hill publications, New Delhi.

Rangavalli, K., Ravisankar, C. and Prasad, P.H. 1993. Post harvest changes in mango (Mangifera indica L.) var. Banesham. South Indian Horticulture 41, pp.160-170.

Romero and Rodriguez 2012. Determination of Vitamin C and Organic acids in various fruits by HPLC' Journal of Chromatographic Science, Vol 30, pp. 433-437.
Salvador, A., Sanz, T. and Fiszman, S.M. 2007. Changes in color and texture and their relationship with eating quality during storage of two different dessert bananas, Post-harvest Biology and Technology, 43, pp.319-325.

Seymour, G.B., Taylor, J.E. and Tucker, G.A. 1993. Biochemistry of Fruit Ripening. Chapman \& Hall, London. pp.107-149.

Sims, G.K. and Gamon, D.S. 2002. Changes in anthocyanin synthesis asan index of maturity in red apple varieties. Journal of Horticultural science, 48, pp.387-392.

Surya and Kumar 2015. Assessment of Banana Fruit Maturity by Image Processing Technique. Journal of food science and technology, 89, pp.331-344.

Sunil Pareek, 2016. Nutritional and Biochemical Composition of Banana (Musa spp.) Cultivars, chapter 3, pp.49-81.

Takeoka, F.R. and Dao, F.D. 2002. Red colour distribution in the skin of 'Gala' apple and some of its sports. N. Z. J. Agric. Res. 29, pp.695-698.

Uddin, M.Z., Rahim, M.A., Alam, M.A., Barman, J.C. and Wadud, M.A. 2006. A study on bio-chemical characteristics of different mango germplasm grown in the climatic condition of Mymensingh. Crop Prod. 1(2), pp.16-19 [Cited from CAB Abst. 2002-2003].

Zomo, S.A., Ismail, S.M., Shah-Jahan, M. and Kabir, M.H. 2014. Chemical Properties and Shelf Life of Banana (Musa sapientum L.) as Influenced by Different Postharvest Treatments. A Scientific Journal of Krishi Foundation. 12(2), pp.6-17. 